\title{
Low-cost metal-forming process using an elastic punch and a reconfigurable multi-pin die
}

\author{
Ali Elghawail ${ }^{1,2} \cdot$ Khamis Essa $^{1}$ (D) $\cdot$ Mohamed Abosaf $^{1} \cdot$ Abror Tolipov $^{1} \cdot$ Shizhong Su $^{1} \cdot$ Duc Pham $^{1}$
}

Received: 23 March 2018 / Accepted: 6 June 2018 / Published online: 27 June 2018

(C) The Author(s) 2018

\begin{abstract}
Due to the need for low-cost tooling and quality parts, a new technique has been developed which brings together the benefits of both multi-point forming (MPF) and rubber-pad forming. A significant disadvantage of MPF is the time required to adjust the heights of the pins in the upper and lower matrices and align the tools. Rubber forming achieves flexibility by replacing one of the MPF pin matrices by an elastic punch. In this study, polyurethane (PU) rubber with a Shore hardness of A90 was adopted as the elastic punch material. The punch was combined with a reconfigurable MPF die to reduce both tool cost and time to set the pins to produce doubly curved parts of acceptable quality. Experimental work has been carried out to confirm the validity of the new technique. Finite element modelling (FEM) using the ABAQUS software was applied to study stress distribution numerically in the formed parts at the end of the forming process. The amounts of wrinkling and springback were employed as criteria to evaluate the quality of the formed part and to compare the results of the current (semi-MPF) approach against full-MPF results. The major outcomes of this study were time and cost reductions of at least $50 \%$ with the added benefits that there is a significant decrease in wrinkling and springback in the final formed part even without using a blank holder.
\end{abstract}

Keywords Elastic punch $\cdot$ Multi-point forming $\cdot$ FEM simulation $\cdot$ Wrinkling $\cdot$ Springback

\section{Introduction}

Flexible metal forming processes, such as multi-point forming (MPF), are employed in manufacturing to reduce the time to market and the cost of production. MPF uses a set of heightadjustable pins to build 3D surfaces, which makes it possible to produce different shapes without having to build a new tool for each one. However, the time consumed to set the pins in the upper and lower matrices to construct the designed shape, and to align the two halves of the tools is considered a significant disadvantage of MPF.

Thiruvarudchelvan has described the history of using flexible tools to form sheet metal and shown that they improve the

Khamis Essa

k.e.a.essa@bham.ac.uk

Ali Elghawail

http://cit.edu.ly

1 School of Mechanical Engineering, University of Birmingham, Edgbaston, Birmingham B15 2TT, UK

2 The College of Industrial Technology, Misrata, Libya surface finish of the final product [19]. They also have the benefit that the forming tool can be easily changed to a new shape without alignment or mismatch issues, which decreases forming tool cost. Material thinning is also reduced by using an elastic punch for metal forming $[15,18]$. The punch can be employed in the same tool set-up to form sheets of different materials and thicknesses [20]. Using hard polyurethane has additional advantages, as the material has the elasticity of rubber and the toughness of metals [8]. However, there are disadvantages with an elastic punch, including limited life depending on process parameters, difficulty with producing sharp features in the final part, and suitability limited to lowvolume or prototype production [16].

Lee, et al. [10] have presented an experimental investigation of flexible forming of aluminium tubing with different bend radii, roller radii and rubber types (Polyurethane with a Shore hardness of A90 and A95). They found that rubber hardness was the most important parameter affecting the radius of the bend. Quadrini, et al. [14] studied the forming of a thin sheet of aluminium alloy utilising various flexible die shapes and materials. They reported that the rubber with highest hardness gave the best results. Chen, et al. [5] investigated the influence of process parameters, such as forming 
speed and compression ratio of the rubber, on the quality of the formed part. They reported that springback of flanging in the rubber forming process was less than that for conventional stamping. Kut and Niedziałek [9] reported that adopting an appropriate hardness for the elastic punch (A90) led to the elimination of defects from the final parts. A theoretical model for static and kinematic friction in the elastic pad forming method by Ramezani et al. [17] gave an improved match between simulation and experimental results. However, previous investigations focused on metal forming by using solid tools with contained rubber pads to produce different shapes.

In this work, a flexible forming setup has been developed by replacing the upper pin matrix with a thick elastic block to form flat aluminium alloy sheets into doubly curved panels. The effects of the elastic punch on the quality of the formed part in terms of wrinkling, springback and forming force were investigated. Experimental work was carried out to validate the proposed approach and to compare the results obtained with those by a full MPF tool.

This paper is structured as follows: Second section introduces the new concept of multi-point elastic forming. Third section describes FE modelling for flexible forming tools and the properties of the metal blank. Fourth section presents the simulation results and fifth section compares them with those obtained experimentally. Six section concludes the paper.

\section{Concept of elastic-punch multi-point forming (EP-MPF)}

Elastic-punch multi-point forming is a sheet metal forming process that combines rubber-pad forming and multi-point forming to gain the advantages of both processes. To prove the EP-MPF process, an experimental model has been developed.

The basic components of the system proposed to form doubly curved panels are shown in Fig. 1. The thick blue element is the elastic punch which replaces the upper MPF pin matrix (the punch) and gives some initial flexibility to the process. The lower matrix of pins is used as the die to form the desired three-dimensional shape. The metal sheet is inserted between the elastic punch and an elastic cushion to prevent dimpling on the surface of the formed part due to the discrete pins forming the matrix. The experimental setup based on this concept was installed on a press as shown in Fig. 2.

The set-up time for the tools required to form the design shape was less than half that for (full or pure) MPF as there is only one matrix of pins to adjust instead of two and the pin alignment process required in MPF using tool guides is not needed. A load cell was used in conjunction with a distance sensor fixed on the press plate to measure punch movement.

\section{FE modelling of EP-MPF}

This section reports on an FE model developed to simulate the concept of EP-MPF and investigate the formed part quality in terms of wrinkling and springback.

The equipment for the new technique was designed to produce panels in aluminium alloy 5251-O. The FE model for EP-MPF combines the MPF die, metal sheet, elastic cushion, elastic block (without container, due to high hardness of polyurethane A90), and press plate, as shown in Fig. 3. In order to reduce the computation time, only a quarter of all components were modelled due to the symmetry of the model.

The MPF die was a matrix of $30 \times 20$ pins, with every pin having a $10 \times 10 \mathrm{~mm}^{2}$ cross-section and a $10 \mathrm{~mm}$ tip radius. Polyurethane A90, a hyper-elastic material, was adopted as the material for both the elastic punch and the elastic cushion in the simulation analysis. The Mooney-Rivlin materials model was chosen among three common models (Mooney-Rivlin,

Fig. 1 Schematic diagram of EPMPF tool

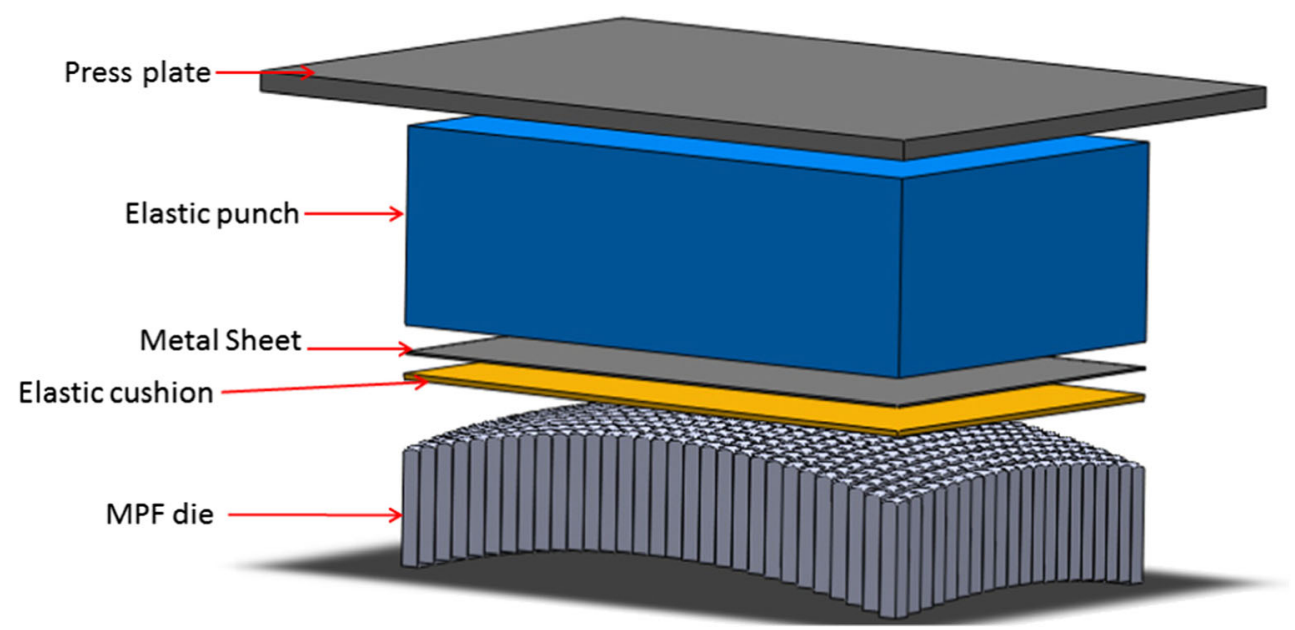


Fig. 2 Experimental setup of EPMPF

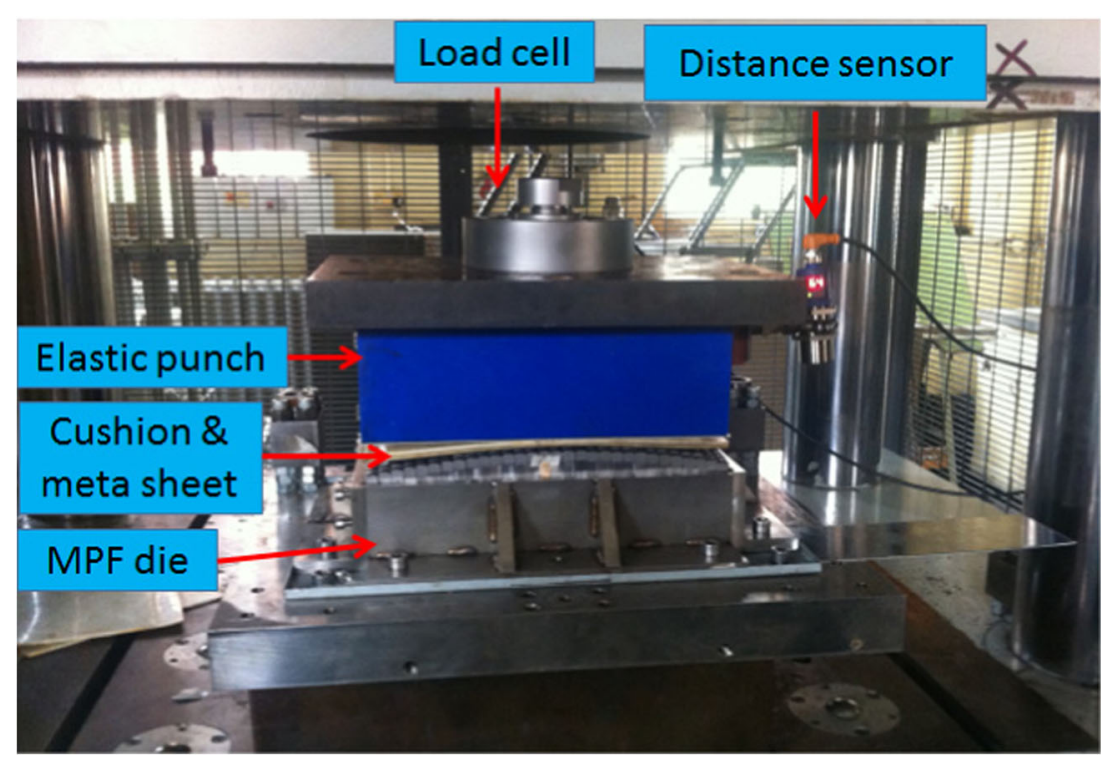

Yeoh and Neo Hook) according to evaluation results by ABAQUS to describe the relation between stress-strain of rubber material $[1,6,8,15]$.

From the constitutive law, the strain energy can be described as:

$\mathrm{W}=\mathrm{C}_{1}\left(\bar{I}_{1}-3\right)+\mathrm{C}_{2}\left(\bar{I}_{2}-3\right)+\frac{1}{D_{1}}(J-1)^{2}$

where $\mathrm{W}$ is the strain energy potential, $\mathrm{C}_{1}$ and $\mathrm{C}_{2}$ are parameters describing the hyper-elastic property of the material, $\overline{I_{1}}$ and $\overline{I_{2}}$ represent the distortion in the rubber, and $J$ is the elastic volume ratio [8]. The properties of aluminium alloy 5251-O sheet are listed in Table 1 [6].

Fig. 3 FE models of EP-MPF techniques
The dimensions of the sheet in the FE models were $153 \times$ $102 \times 1.2 \mathrm{~mm}$ thick. The elastic cushion dimensions were $153.5 \times 102.5 \times 6 \mathrm{~mm}$ thick, and the elastic punch was 153 $\times 102 \times 100 \mathrm{~mm}$ thick. The three components were modelled using deformable solid elements, and the C3D8R element type was used as recommended by Wang et al. [21]. A total of 47,124 elements were employed to mesh a quarter of the sheet. A total of 95,172 elements were used to mesh the elastic cushion, and 200,277 elements were used to mesh the elastic punch. Finally, the MPF die was modelled as discrete rigid bodies and the R3D4 element type was used as recommended by Zareh-Desari et al. [22]. The press plate was modelled as part of a shell to save calculation time. A general contact algorithm was utilized to model the interaction between pins

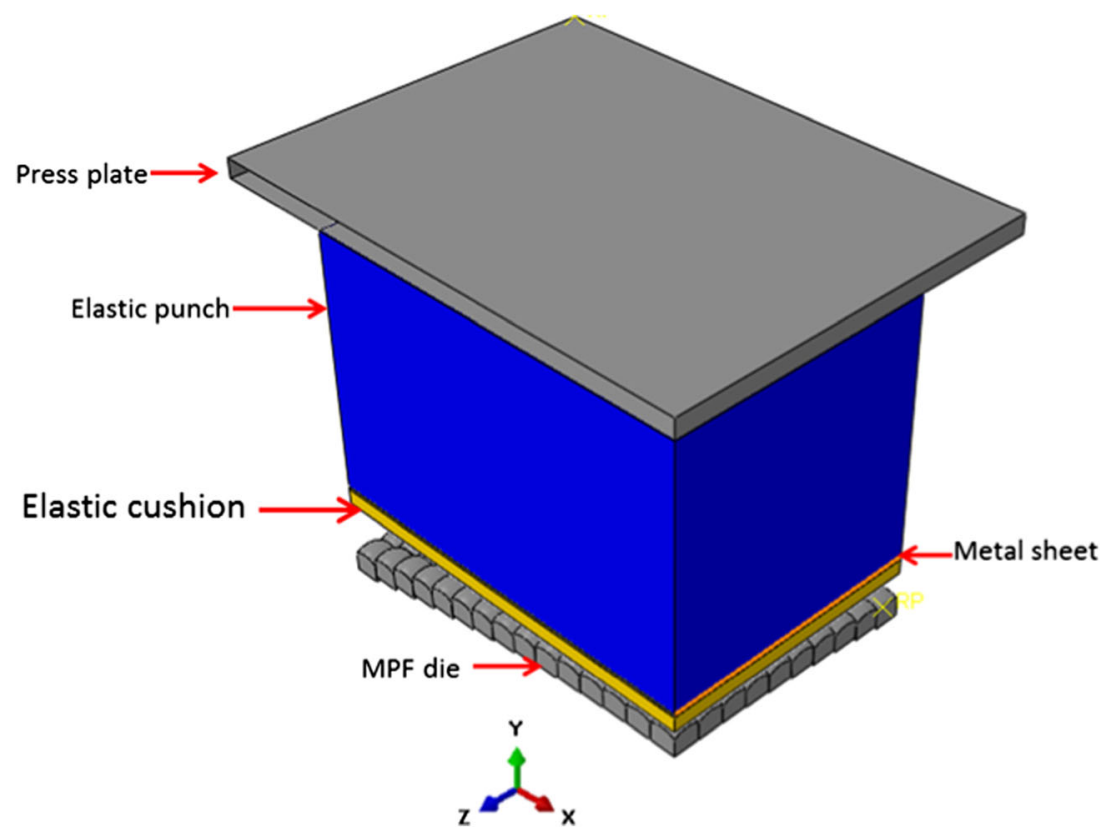


Table 1 Mechanical properties of aluminium alloy 5251-O

\begin{tabular}{ll}
\hline Property & Value \\
\hline Density $(\rho)$ & $2700 \mathrm{~kg} / \mathrm{m}^{3}$ \\
Modulus of elasticity $(E)$ & $65 \mathrm{Gpa}$ \\
Yield stress $(\sigma)$ & $100.2 \mathrm{Mpa}$ \\
Poisson's ratio $(\nu)$ & 0.33 \\
Hardening coefficient $(K)$ & $270 \mathrm{Mpa}$ \\
Hardening exponent $(n)$ & 0.45 \\
\hline
\end{tabular}

and elastic cushion, and between the metal sheet and the rubber. A coefficient of friction of 0.25 was used [15].

As the assembly was constructed assuming symmetry, symmetric boundary conditions were applied to the metal sheet, elastic cushion and elastic punch. The MPF die node was fixed in the $\mathrm{X}, \mathrm{Y}$ and $\mathrm{Z}$ directions. As mentioned previously, the elastic punch was not placed within a rigid container. Therefore, the forming force was applied as a given movement to the press plate node in the Y-direction, as shown in Fig. 4.

ABAQUS/Explicit Dynamic was used to analyse the sheet metal forming step where the elastic punch moves down against the MPF die to form the sheet, while the unloading or recovery step where the forming forces are released was solved using ABAQUS/Standard [21], and the nodal displacement in Y- direction after unloading was considered to represent springback value [11].

\section{Experimental results and discussion}

Figure 5 presents sample parts formed using the new technique and those produced by the MPF process in a previous study by Abosaf, et al. [6]. A FARO Edge 3D scanner with

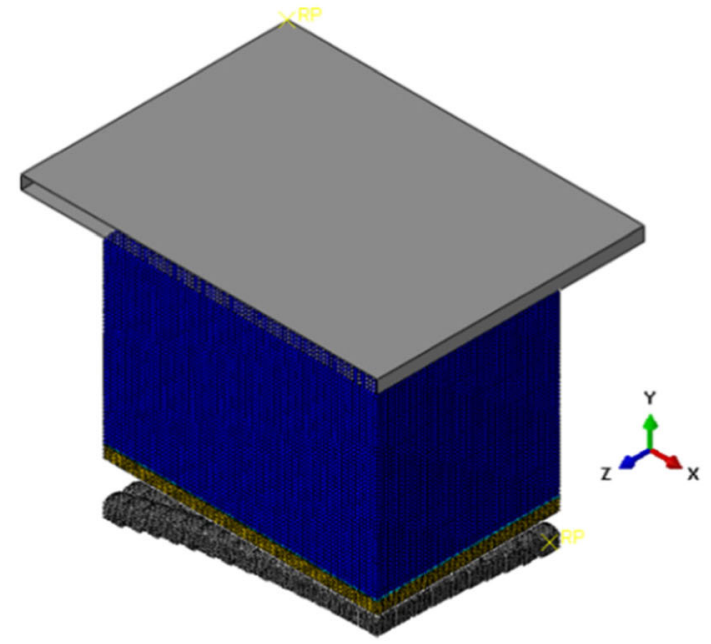

Fig. 4 Mesh elements and boundary conditions in FE model
Geomagic control was employed to capture the shape of the final product to determine deviations between it and the designed part [7].

For the part with $400 \mathrm{~mm}$ radius of curvature, the normal distance between the target and formed shapes at regular intervals along path $\mathrm{O}-\mathrm{C}$ as shown in Fig. 6 was determined, and the way how to measure the wrinkling value between designed part and the part produced by two techniques is shown in Fig. 7. The root mean square error (RMSE) was used to calculate a numerical value for wrinkling [1].

In the case of the formed part with $800 \mathrm{~mm}$ radius of curvature, the captured points were compared to the ideal shape and the deviation in the Y-direction along path O-B was used to represent the springback [6] as shown in Fig. 8.

\section{Simulation results and discussion}

The forming process using an elastic punch can be divided into three steps. The first step is self-deformation of the elastic punch; the second step is sheet deformation under the forming force of the elastic punch until the sheet is shaped into the MPF die cavity and, the third and final step is the unloading stage (i.e. load release).

\section{Comparison of simulated forming forces for EP-MPF and MPF}

Figures 9 and 10 show the forming force- versus time curves for two parts with different radius of curvature produced by EP-MPF and MPF. The MPF forming force had been measured experimentally in previous work, by Elghawail, et al. [6]. As can be seen in the two figures, there are significant differences between the values and trends of the forming force

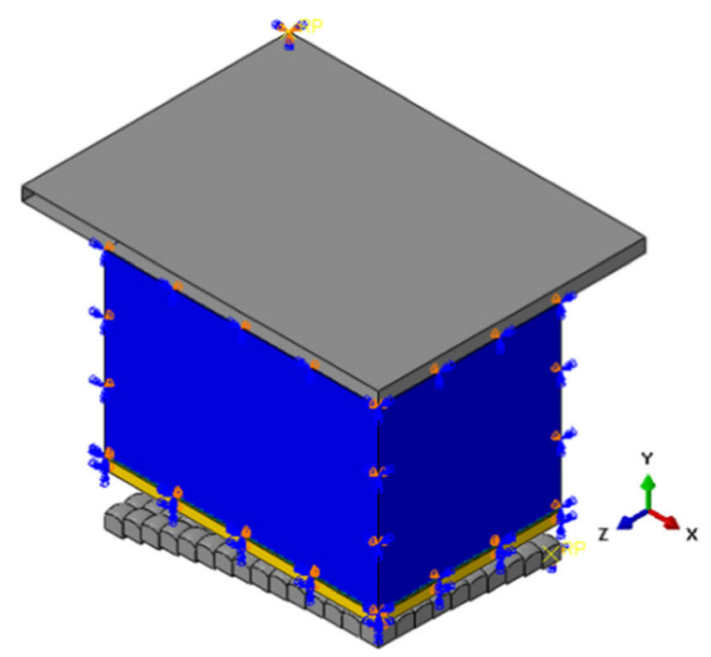


Fig. 5 Sample parts fabricated by MPF and EP-MPF

MPF process

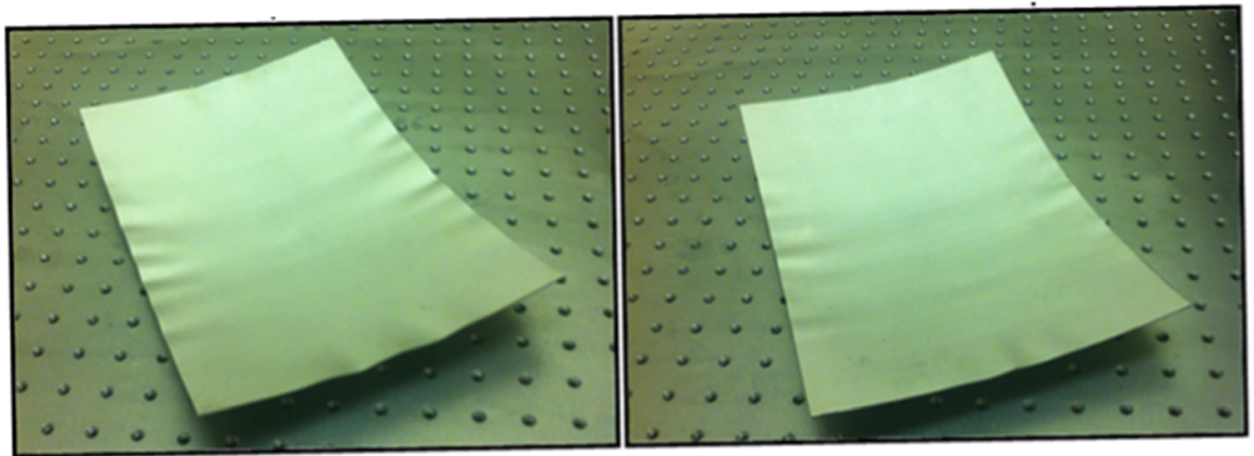

Radius of curvature $400 \mathrm{~mm}$
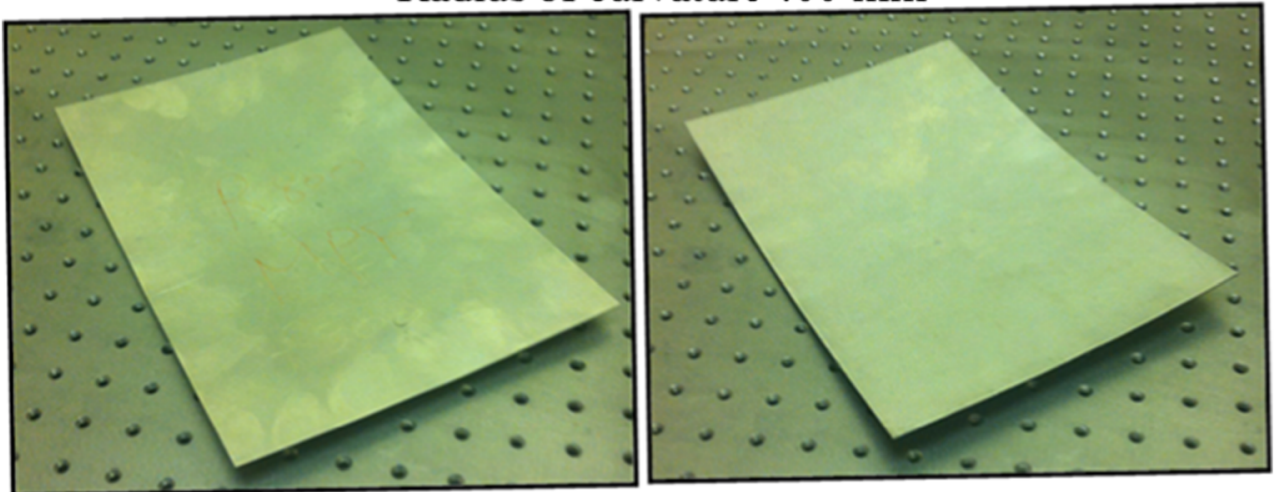

\section{Radius of curvature $800 \mathrm{~mm}$}

to produce the same part from a $1.2 \mathrm{~mm}$ thick sheet of aluminium alloy 5251-O. This difference is due to the nature of the new forming approach. The punch is made from an elastic material, which begins deformation at early stage of the process. This leads to the force to rise gradually and smoothly from the beginning until the end of the process. On the other hand, in conventional MPF, the forming force rise slowly at the beginning of the process and increases rapidly when maximum plastic deformation is reached towards the end of the process.

The forming force required in EP-MPF rose to $90 \mathrm{kN}$ to produce the part with $800 \mathrm{~mm}$ radius of curvature. However, with the MPF punch, it only reached $50 \mathrm{kN}$ [2]. The forming forces followed very different trends. In the case of the elastic punch (EP-MPF), the evolution of the forming force can be divided into three stages. In the initial $15 \mathrm{~s}$, when the elastic punch first contacted the sheet, the forming force was very small. It then gradually increased due to self-deformation of the elastic punch; also, the sheet was bending as the punch moved forward into the die; this process extended from about $15 \mathrm{~s}$ to approximately $1 \mathrm{~min}$. Finally, the forming force continued to rise due to plastic deformation of the sheet as it moved to copy the shape of the die cavity and more pressure was applied on the punch to make sure the die was fully covered [12]; this occupied the last 2 min of the process.

In the case of the MPF punch, the forming force remained very small until close to the end of the process when it
Fig. 6 Wrinkling at edge of formed part $(R=400 \mathrm{~mm})$

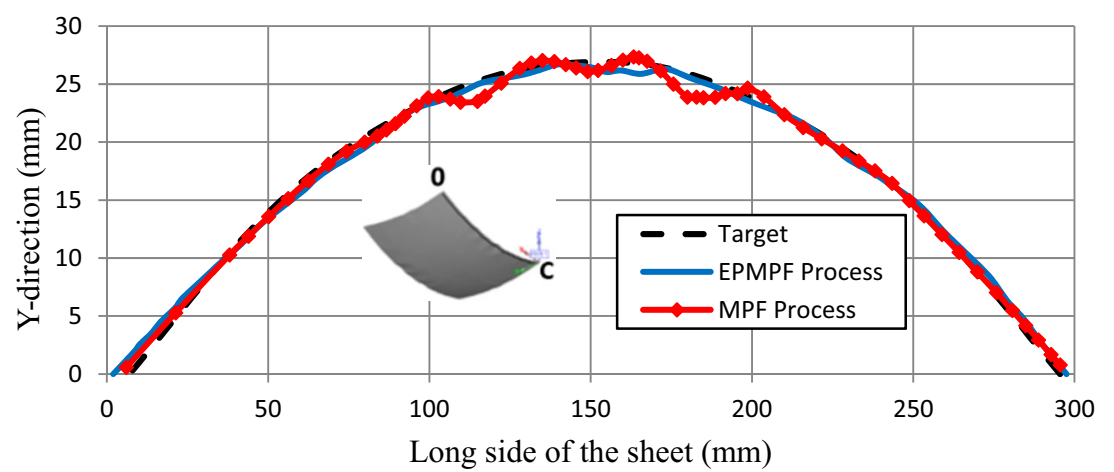


Fig. 7 Wrinkling measured method [1]

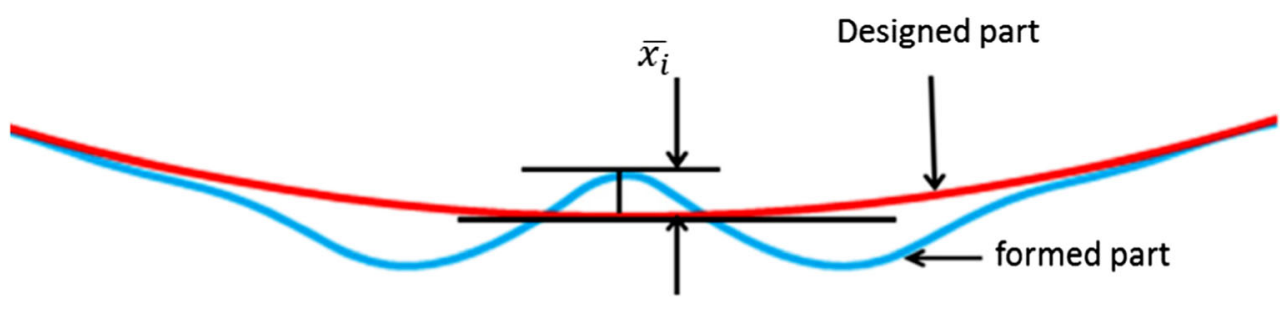

Fig. 8 Springback of formed part along path O-B $(R=800 \mathrm{~mm})$

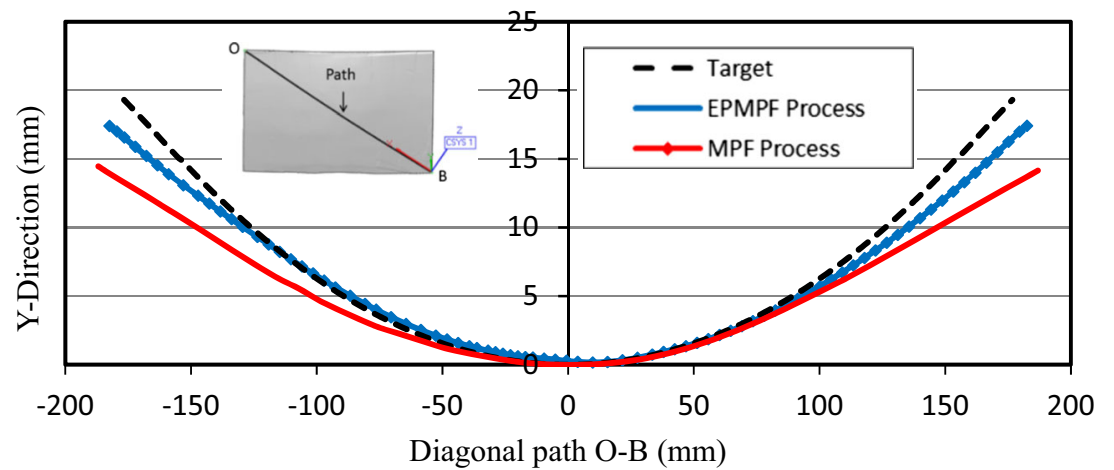

suddenly increased as the sheet started to deform. The same explanations apply to the part with $400 \mathrm{~mm}$ radius of curvature.

It can be seen that in the case of the MPF punch, the total forming force increased with the radius of curvature. This result was due to more pins coming into contact with the sheet at the beginning of the forming process [1]. With the elastic punch, there was an increase in the forming force with a decrease in the radius of curvature. This was because more force was needed to push the rubber forward to cover the entire MPF die.

\section{Stress distribution on top and bottom surfaces of the formed sheet}

FE models were developed for two panels and analysed using ABAQUS. The calculated pressure distributions on the top and bottom surfaces of the sheet at the end of the forming process are shown in Figs. 11 and 12.

Figure 11 shows pressure distributions on the formed part with $400 \mathrm{~mm}$ radius of curvature using MPF and EP-MPF. Large bending deformations were required in this case [1] and, as can be seen, the stresses in the part formed by EP-MPF were well distributed compared with those produced by the MPF punch.

This was because the elastic punch deformed together with the sheet metal during the loading step, which means the relative motion between the punch and the sheet was very small and the influence of frictional forces was, therefore, negligible. However, as the MPF punch was rigid, relative motion at the interface was much larger and the presence of friction made it more difficult for the blank material to flow, especially when the friction coefficient was high [13]. This led to stress instability and wrinkling $[1,3]$. In both cases, in the middle of
Fig. 9 Forming force-time curve for radius of curvature $800 \mathrm{~mm}$

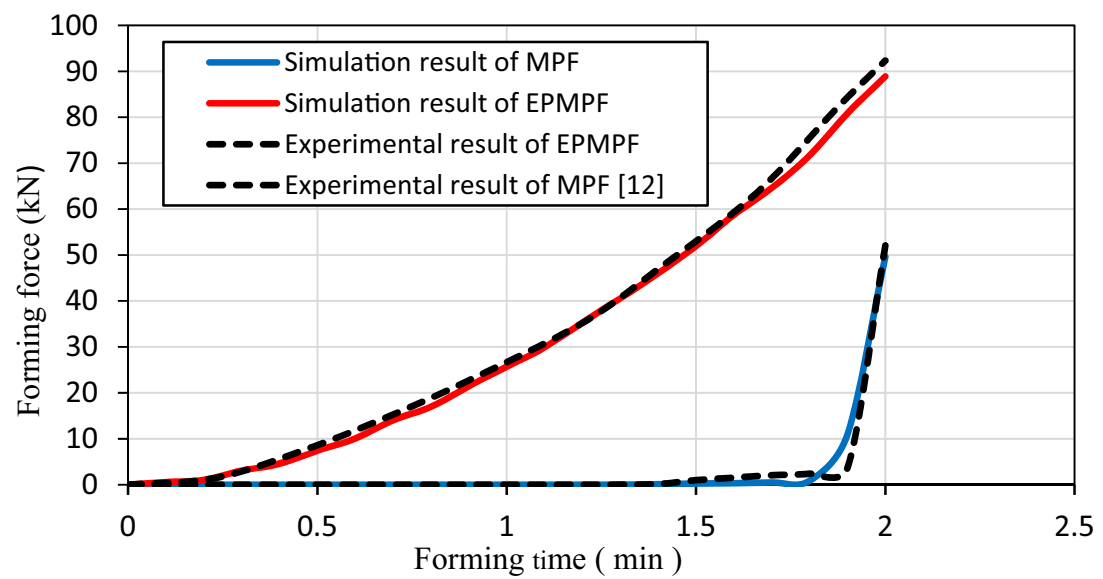




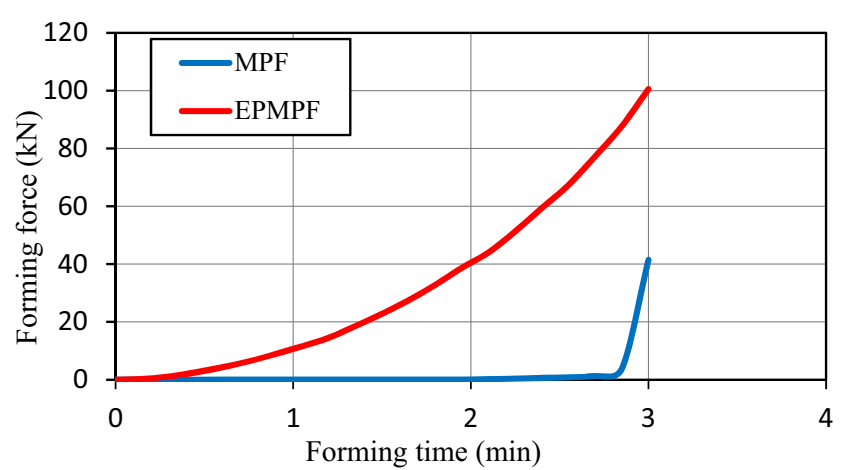

Fig. 10 Forming force- time curve for $400 \mathrm{~mm}$ radius of curvature

the long edge, it is clear that the stresses fluctuated between maximum and minimum values, causing wrinkling [1, 3]. However, the wrinkling amplitudes were smaller with the elastic punch than with the MPF punch.

For the part with the larger radius of curvature of $800 \mathrm{~mm}$ which required less bending deformation, the results are shown in Fig. 12. Here, the pressure distributions on the top and the bottom surfaces of the part was more uniform (which is the key to controlling springback) with EP-MPF than with
MPF. This uniformity leads to stress stability, attenuation of wrinkling waves and reduction in springback value in the part formed by EP-MPF compared to that produced by the MPF.

\section{Wrinkling}

The comparison of wrinkling profile for both simulation and experimental results has been plotted in Fig. 13. The result shows good argument which it gives the reliability of experimental outcomes.

Simulation results for parts with $400 \mathrm{~mm}$ radius of curvature produced by MPF and EP-MPF show that wrinkling can be significantly reduced by using an elastic punch with Shore hardness A 90 [9], as shown in Fig. 13 along path O-C.

In this work, as shown in Fig. 7, the distances between the formed and target shapes at the peaks of the wrinkles were used to measure wrinkling.

The root mean square error (RMSE), computed using those distances, was taken as the total amount of wrinkling (Eq. (2)).

$R M S E=\sqrt{\frac{1}{n} \sum_{i=1}^{n} x_{i}^{2}}$

\section{EPMPF process}

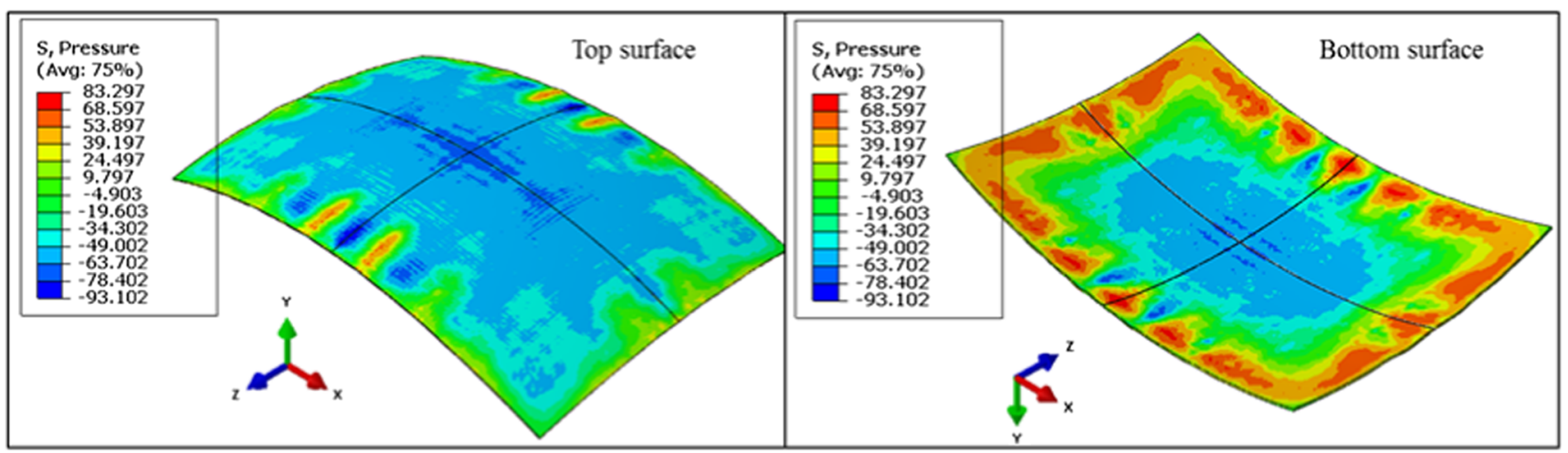

\section{MPF process}

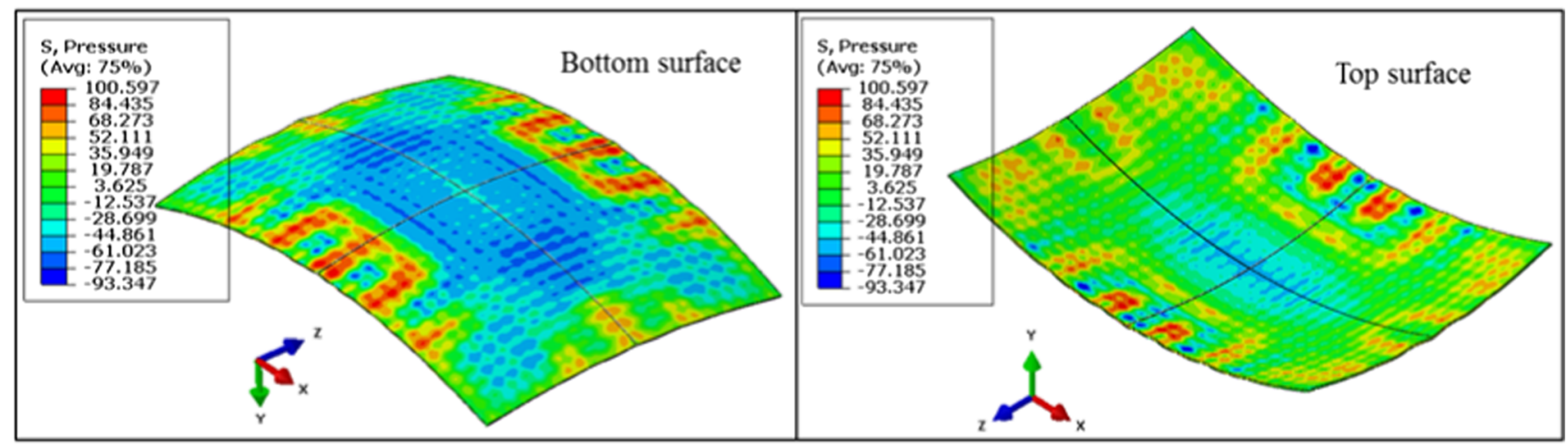

Fig. 11 Pressure distributions on top and bottom surfaces of formed part before springback $(R=400 \mathrm{~mm})$ 


\section{EPMPF process}

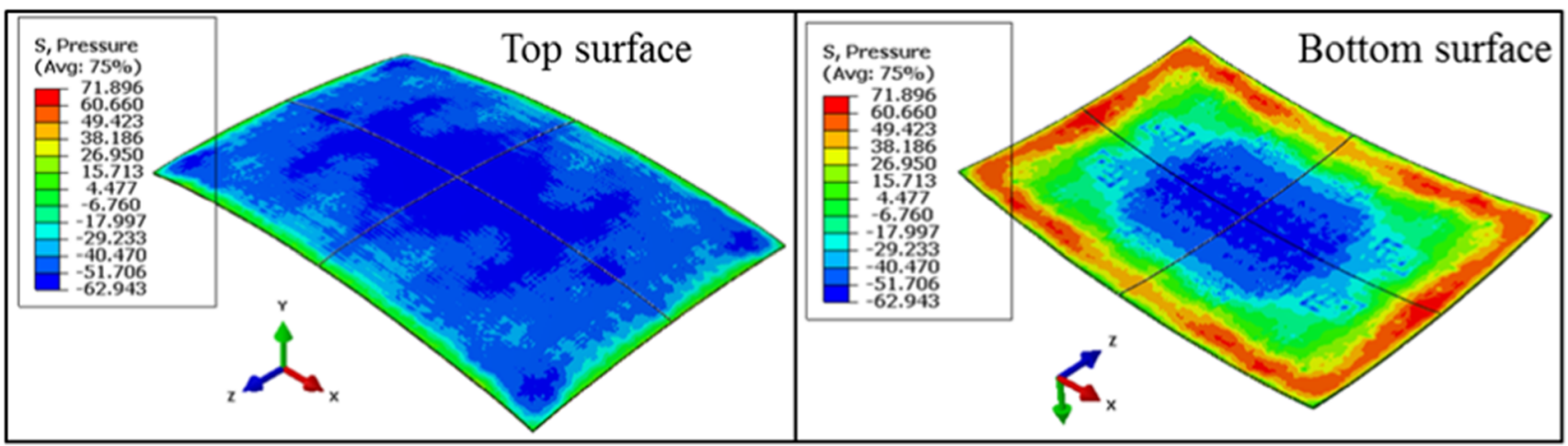

\section{MPF process}

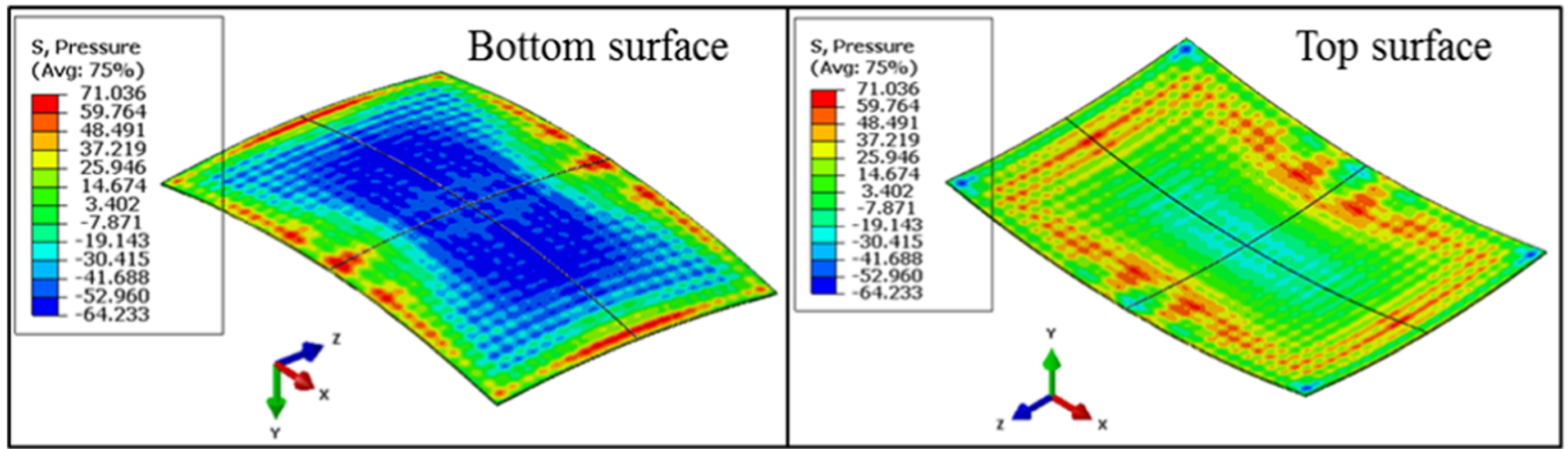

Fig. 12 Pressure distributions on top and bottom surfaces of formed part before springback $(R=800 \mathrm{~mm})$

Where $\mathrm{n}$ is the number of wrinkling waves, and $x_{i}$ is the difference between the magnitude of the wrinkle and the target curve at the $\mathrm{i}^{\text {th }}$ peak.

The RMSE value for wrinkling when using the MPF punch was $1.30 \mathrm{~mm}$ and that obtained with the elastic punch was $0.534 \mathrm{~mm}$, which is a significant reduction (Fig. 14).

\section{Springback}

In order to study the effect of the elastic punch on springback, a comparison between the post-springback part and the final part was carried out.

Fig. 13 wrinkling comparison for EP-MPF
Figure $15 \mathrm{a}$ and $\mathrm{b}$ show the simulation results for springback in the formed part with radius of curvature $800 \mathrm{~mm}$ produced by the two techniques. From Fig. 15a and $b$, respectively, it can be seen that the MPF part had a total springback of $6.21 \mathrm{~mm}$ and the EP-MPF part had a total springback of $3.66 \mathrm{~mm}$. Thus, springback for the elastic punch was significantly smaller. These results are also related to uniformity of stress distribution and friction, which is considered of major importance in determining springback phenomena. The more uniform the stress and friction conditions, the less the springback variation $[4,5]$. In the case of friction, for the elastic punch, the

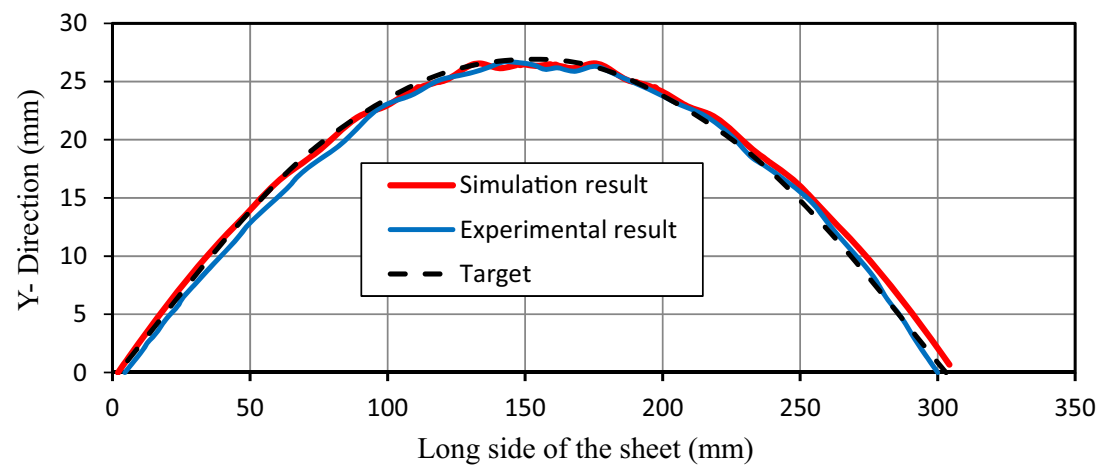


Fig. 14 Wrinkling simulation results for two different forming techniques $(R=400 \mathrm{~mm})$ [6]

\begin{tabular}{|l|}
\hline PEEQ \\
(Avg: 75\%) \\
O.059 \\
\hline 0.054 \\
0.050 \\
0.045 \\
0.040 \\
0.035 \\
0.030 \\
0.025 \\
0.020 \\
0.015 \\
0.010 \\
0.005 \\
0.000 \\
\hline
\end{tabular}

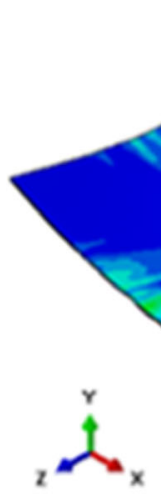

MPF C

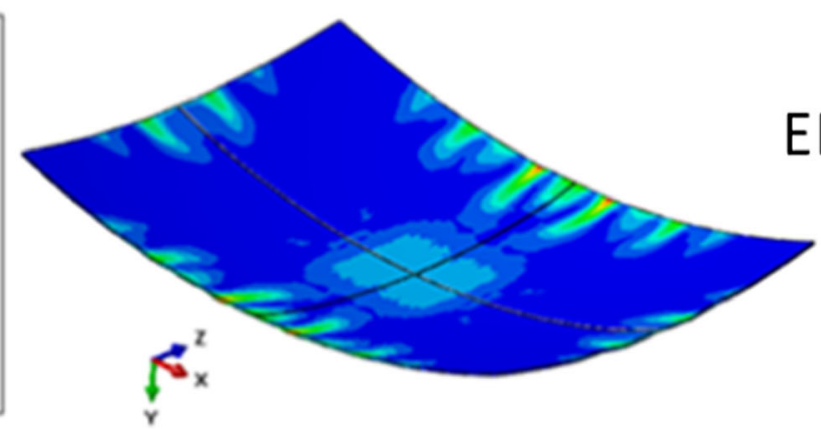

EPMPF
Fig. 15 a and $\mathbf{b}$ Springback simulation results for workpiece formed by MPF and EP-MPF

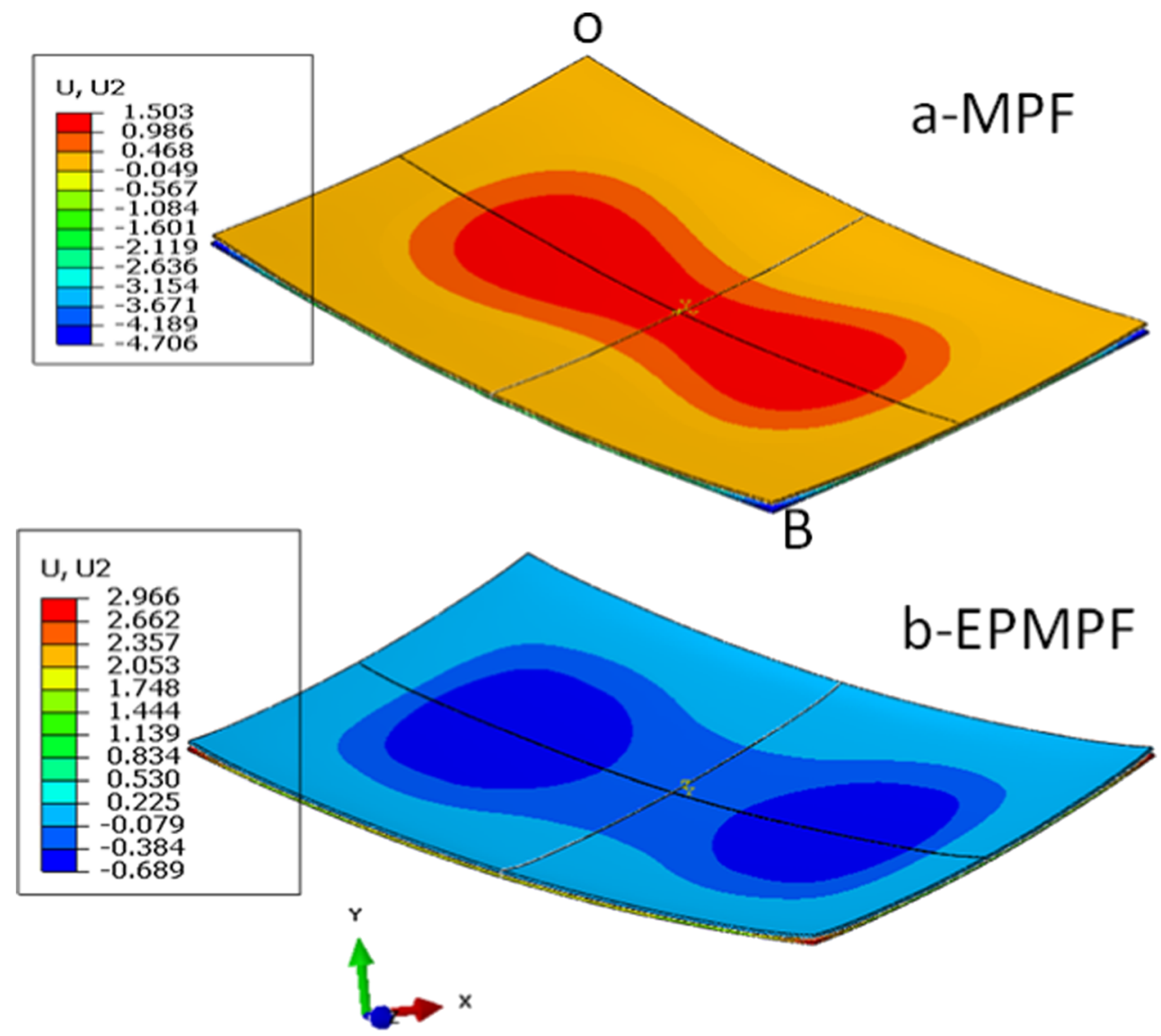


Fig. 16 Springback of part formed by MPF $(R=800 \mathrm{~mm})$

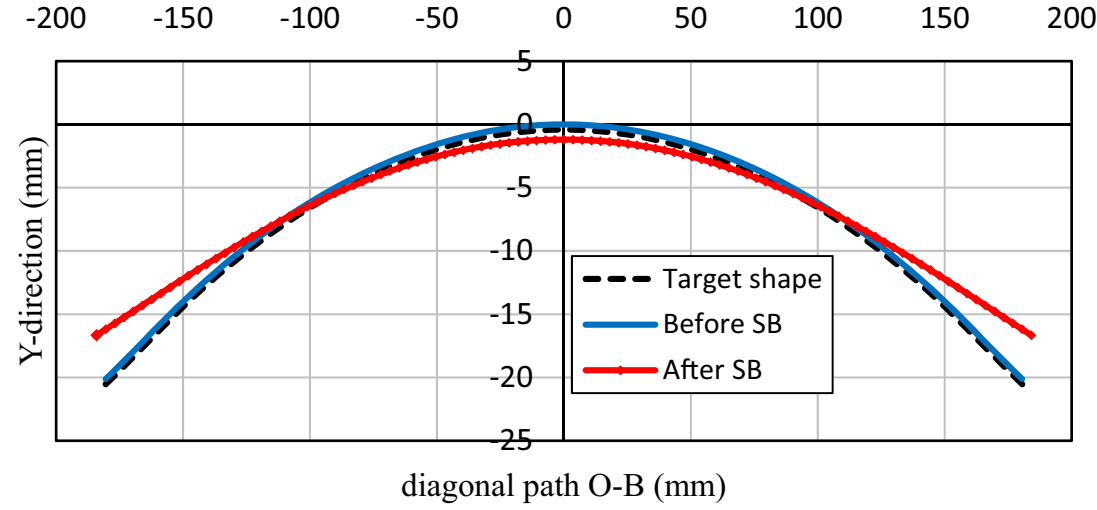

relative motion and the friction force between the punch and the top surface of the formed sheet are less than in the case of the MPF punch, where relative motion and friction are concentrated on the tip of the pins and are affected by the properties and thickness of the elastic cushion.

Figures 16 and 17 show the target shape, the computed shape, the computed shape at the end of the application of the forming force before springback and the computed shape post-springback for the two forming techniques.

\section{Conclusion}

Doubly curved panels were produced from $1.2 \mathrm{~mm}$ thick aluminium 5151-O sheets by elastic punch-multi-point forming (EP-MPF) using dies with two different radii of curvature. Experimental work was carried out to demonstrate the concept and numerical simulation conducted to obtain the stresses on the formed parts. In order to check the quality of final parts produced by EP-MPF, a comparison was carried out between pure multi-point forming (MPF) and EP-MPF in terms of wrinkling, springback and forming force. One of the punches used had a small radius of curvature and the other had twice the curvature. Based on results obtained from testing the forming techniques, the following conclusions can be drawn from this study:

1- Replacing a MPF punch with an elastic punch, reduced tooling costs by approximately $50 \%$ and dramatically decreased the setup time needed to adjust the pins to the design shape.

2- In conventional MPF, it is necessary to change the pins configuration if the thickness of the metal sheet is changed. However, in EP-MPF, the same tooling can be employed to different thicknesses without changing the die setup.

3- Wrinkling of the final part can be reduced significantly with a $400 \mathrm{~mm}$ radius of forming curvature without the use of a blank holder compared to the part produced by conventional MPF punch.

4- Replacing MPF with EP-MPF also significantly reduced springback of the formed part.

Further work is needed to investigate the effect of elastic punch thickness and compression ratio on the quality of formed parts, in terms of wrinkling, springback and forming force.
Fig. 17 Springback of part formed by EP-MPF $(\mathrm{R}=$ $800 \mathrm{~mm})$

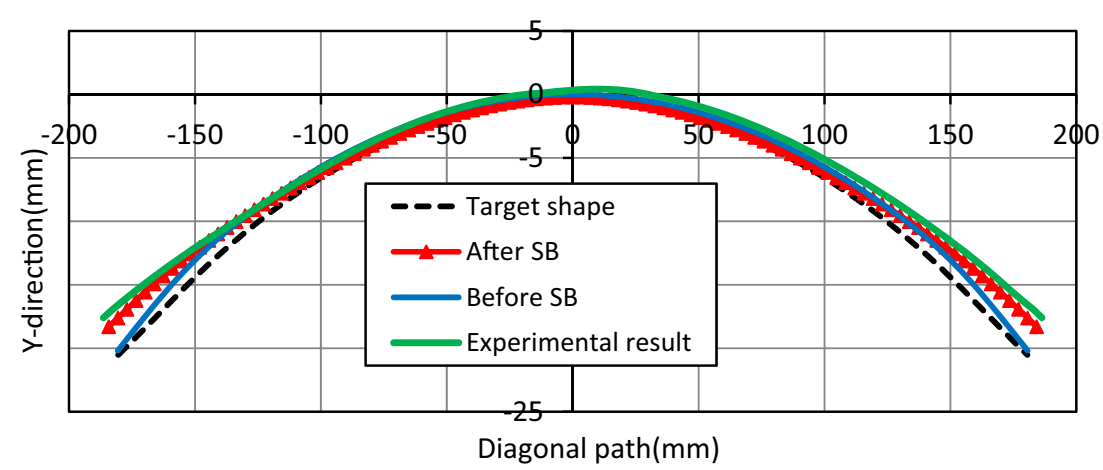


Acknowledgements This work was part of the "Automated Manufacturing Process Integrated with Intelligent Tooling Systems (AUTOMAN)" project supported by the Engineering and Physical Sciences Research Council and Innovate UK (Grant Reference EP/ L505225/1).

\section{Compliance with ethical standards}

Conflict of interest None.

Open Access This article is distributed under the terms of the Creative Commons Attribution 4.0 International License (http:// creativecommons.org/licenses/by/4.0/), which permits unrestricted use, distribution, and reproduction in any medium, provided you give appropriate credit to the original author(s) and the source, provide a link to the Creative Commons license, and indicate if changes were made.

Publisher's Note Springer Nature remains neutral with regard to jurisdictional claims in published maps and institutional affiliations.

\section{References}

1. Abosaf, M., 2018. Finite element modelling of multi-point forming, $\mathrm{PhD}$ Thesis, University of Birmingham, Birmingham

2. Belhassen L, Koubaa S, Wali M, Dammak F (2016) Numerical prediction of springback and ductile damage in rubber-pad forming process of aluminum sheet metal. Int J Mech Sci 117:218-226

3. Cai ZY, Wang SH, Li MZ (2008) Numerical investigation of multipoint forming process for sheet metal: wrinkling, dimpling and springback. Int J Adv Manuf Technol 37(9-10):927-936

4. Chen PKM, Wenner ML (2008) Experimental investigation of springback variation in forming of high strength steels. J Manuf Sci Eng 130(4):041006

5. Chen L, Chen H, Guo W, Chen G, Wang Q, (2014)Experimental and simulation studies of springback in rubber forming using aluminium sheet straight flanging process. Materials \& Design (19802015). 54:354-360

6. Elghawail A, Essa K, Abosaf M, Tolipov A, Su S, Pham D (2017) Prediction of springback in multi-point forming. Cogent Engineering 4(1): 1400507

7. http://www.faro.com/products/metrology/faro-scanarm/overview\# main., a.o., accessed on 13/01/2017
8. Irthiea, I.K., 2014, Process analysis and design in micro deep drawing utilizing a flexible die. University of Glasgow: Doctoral dissertation

9. Kut S, Niedziałek B (2015) Numerical and experimental analysis of the process of aviation Drawpiece forming using rigid and rubber punch with various properties. Arch Metall Mater 60(3):1923-1928

10. Lee J et al (2003) Determination of forming limit of a structural aluminum tube in rubber pad bending. J Mater Process Technol 140(1):487-493

11. Li L, Seo YH, Heo SC, Kang BS, Kim J (2010) Numerical simulations on reducing the unloading springback with multistep multi-point forming technology. Int J Adv Manuf Technol 48(1):45-61

12. Liu Y, Lin H, Lan J, Wei X (2010) Studies of the deformation styles of the rubber-pad forming process used for manufacturing metallic bipolar plates. J Power Sources 195(24):8177-8184

13. Peng $\mathrm{L}$ et al (2010) Fabrication of metallic bipolar plates for proton exchange membrane fuel cell by flexible forming processnumerical simulations and experiments. Journal of Fuel Cell Science and Technology 7(3):031009

14. Quadrini F, Santo L, Squeo EA (2010) Flexible forming of thin aluminum alloy sheets. Int J Mod Manuf Technol 2(1):79-84

15. Ramezani M, Ripin Z, Ahmad R (2009) Numerical simulation of sheet stamping process using flexible punch. Proc Inst Mech Eng B J Eng Manuf 223(7):829-840

16. Ramezani M, Ripin ZM, Ahmad R (2010) Sheet metal forming with the aid of flexible punch, numerical approach and experimental validation. CIRP J Manuf Sci Technol 3(3):196-203

17. Remezani M, Ripin ZM, Ahmed R (2009) Computer aided modelling of friction in rubber-pad forming process. J Mater Process Technol 209(10):4925-4934

18. Sala G (2001) A numerical and experimental approach to optimise sheet stamping technologies: part II—aluminium alloys rubberforming. Mater Des 22(4):299-315

19. Thiruvarudchelvan $S$ (1993) Elastomers in metal forming: a review. J Mater Process Technol 39(1):55-82

20. Thiruvarudchelvan S (2002) The potential role of flexible tools in metal forming. J Mater Process Technol 122(2):293-300

21. Wang S, Zhongyi C, Mingzhe L, Lan Y (2012) Numerical simulation on the local stress and local deformation in multi-point stretch forming process. Int J Adv Manuf Technol 60(9-12):901-911

22. Zareh-Desari B, Davoodi B, Vedaei-Sabegh A (2017) Investigation of deep drawing concept of multi-point forming process in terms of prevalent defects. Int J Mater Form 10(2): 193-203 